\title{
SHOULD BITCOIN BE HELD UNDER THE U.S. PARTISAN CONFLICT?
}

\author{
Chi-Wei SU ${ }^{1}$, Meng QIN² ${ }^{*}$ Xiao-Lei ZHANG ${ }^{3}$, \\ Ran $\mathrm{TAO}^{4}$, Muhammad UMAR ${ }^{5}$ \\ ${ }^{1,2,5}$ School of Economics, Qingdao University, 62 Kedazhi Rd., Qingdao, Shandong, China \\ ${ }^{3}$ Postal Savings Bank of China, Yantai, China \\ ${ }^{4}$ Qingdao Municipal Center for Disease Control \& Preventation, Qingdao, China
}

Received 26 February 2020; accepted 24 October 2020

\begin{abstract}
This paper probes the interrelationship between Bitcoin price (BP) and the U.S. partisan conflict (PC) by performing the bootstrap full- and sub-sample Granger causality tests. The positive influence from PC to $\mathrm{BP}$ reveals that Bitcoin can be considered as a tool to avoid the uncertainty caused by the rise in PC. However, this view cannot be supported by the negative impact, the major reason is that the burst of bubble undermines the hedging ability of Bitcoin. The above results are inconsistent with the intertemporal capital asset pricing model (ICAPM), underlining that high PC may drive BP to rise, in order to compensate for the losses and costs from factionalism. Conversely, BP has a negative impact on PC, suggesting that the U.S. political situation can be reflected by the Bitcoin market. Under the circumstance of the fiercer factionalism in the U.S., this investigation can benefit investors and related authorities.
\end{abstract}

Keywords: Bitcoin price, U.S. partisan conflict, rolling- window, dynamic nexus.

JEL Classification: C32, G12, P16.

\section{Introduction}

The primary target is to quest whether Bitcoin is the winner after the U.S. factionalism, also indicating that Bitcoin can be viewed as a tool to avoid uncertainty caused by partisan conflict (PC). Since the birth of Bitcoin, it attracts great attention by investors, the appearances of the regular exchanges make its transactions more convenient (Elwell et al., 2013; Pyo \& Lee, 2019). Thereby, Bitcoin and its market have experienced dramatic growth, also it can be viewed as a hedging asset during certain periods (Bouoiyour et al., 2019; Fang et al., 2019; Kalyvas et al., 2019; Mamun et al., 2020; Qin et al., 2020), which include the situations with high PC. If the factionalism is fierce, investors are inclined to store assets with hedging capacity (Jiang et al., 2020), such as Bitcoin. Then, the increasing demand for Bitcoin drives

*Corresponding author. E-mail: meng575316928@126.com

Copyright $\odot 2021$ The Author(s). Published by Vilnius Gediminas Technical University

This is an Open Access article distributed under the terms of the Creative Commons Attribution License (http://creativecommons. org/licenses/by/4.0/), which permits unrestricted use, distribution, and reproduction in any medium, provided the original author and source are credited. 
Bitcoin price (BP) to rise, and this view can be observed in several circumstances. In 2013, both Cyprus which asks for European Union (UN) assistance, and Germany which is the main donor, have ushered in an election year. These elections, as well as the Cyprus crisis and the eurozone rescue operations, make factionalism in these two countries fiercer. In order to avoid risks of the Cyprus crisis and the uncertainty caused by the high PC, investors are more inclined to hold Bitcoin, driving BP to soar (Luther \& Salter, 2017). A referendum vote on Brexit has taken place in 2016, the political parties in the U.K. unable to reach consensus, which causes PC to increase sharply (Ron et al., 2018). The demand for Bitcoin and BP have increased during this time since the Brexit and high PC bring huge uncertainty and panic. Thus, we can conclude that Bitcoin is the winner after the factionalism, but this conclusion does not always hold. The Bitcoin bubble bursts in 2018, leading BP to plummet (Li et al., 2018; Xiong et al., 2019), even if PC is high in several countries, such as the U.S. (e.g., SinoU.S. trade frictions and government shutdown) and South Korea (e.g., head-on collision at Liberal Korean Congress). In turn, Bitcoin has been involved in the elections in some countries or regions, such as Sweden, Ireland and the U.S. states, indicating that Bitcoin market may be a leading factor of the political situation. In general, whether Bitcoin is the winner after the factionalism is an important issue, which has not been explained clearly. Thus, this paper explores the time-varying correlation between $\mathrm{BP}$ and $\mathrm{PC}$ to solve this issue. The interrelationship between $\mathrm{BP}$ and $\mathrm{PC}$ can provide insights for investors to enhance their returns by storing Bitcoin and preventing blind speculation. Also, it can give lessons to the related authorities to achieve national stable growth by avoiding the large fluctuations in the Bitcoin market, as well as enhancing the citizen support for the government.

As the largest economy in the world, U.S. politics has been featured by a fierce PC (Azzimonti, 2014; Gupta et al., 2017). The fluctuations in PC also have significant effects on various aspects, such as Euro area economy (Cheng et al., 2016), Sino-U.S. bilateral trade (Jiang \& Shi, 2018), financial market (Gupta et al., 2018a, 2018b), foreign direct investment (Azzimonti, 2019), as well as the international oil price (Cai \& Wu, 2019; Su et al., 2020c). More importantly, PC has a relation with BP, and we can observe this interaction from five sides. Firstly, the U.S. government shutdown causes PC to rise (Azzimonti, 2014), which may increase the demand for Bitcoin to hedge risks, then driving BP to soar. This view can be proved in the 2013 government shutdown, but BP and PC move in the different directions in 2018 one. Secondly, the presidential election, which is accompanied by a high PC (Azzimonti, 2014), brings uncertainty to the investors, determining them more willing to hold Bitcoin. Then, the rise in Bitcoin demand leads BP to increase, which can be evidenced in the 2016 presidential election (Donald Trump vs. Hillary Clinton). Thirdly, economic policy uncertainty also affects the interaction between PC and BP, which can be understood in two aspects. To begin with, BP is denominated in U.S. dollars, and there is a negative relationship between BP and the U.S. dollars (Dyhrberg, 2016; Baur et al., 2018; Qin et al., 2020). The economic policies, such as raising the interest rates, may increase PC and the value of the U.S. dollars (Bartsch, 2019), then BP decreases. On the other hand, the trade policies (e.g., SinoU.S. trade frictions) also have significant effects on the mutual influence between PC and BP. Fourth, the wars, conflicts or tensions launched by the U.S. not only cause PC to rise but also increase the geopolitical risks (Caldara \& Iacoviello, 2017; Su et al., 2020c, 2020d). These risks 
make investors more willing to store Bitcoin, which can be verified during the period of the sanctions against Iran in 2019. Fifth, the public health events, such as corona virus disease 19 (COVID-19), also have certain impacts on the relationship between the Bitcoin market and the U.S. political environment. Furthermore, as some candidates accept Bitcoin donation in the U.S., the Bitcoin market may reflect the U.S. political situation. Thus, there may be an association between Bitcoin market and the U.S. factionalism, but the time-varying nexus between them is ignored by the existing studies, and this paper tries to fill this gap.

This paper has some innovations or contributions. First of all, the previous researches have focused more on exploring the relationship between uncertainty and Bitcoin market (Bouri et al., 2017; Bouoiyour et al., 2019; Bouri \& Gupta, 2019; Qin et al., 2020), and hardly investigate the mutual influence between BP and PC. This study is a groundbreaking work to probe whether Bitcoin is the winner after the U.S. factionalism and what role of BP in reflecting the political environment. The empirical results suggest that $\mathrm{PC}$ has positive and negative influences on BP, and BP negatively affects PC. The above conclusions are supported by the intertemporal capital asset pricing model (ICAPM), underlining that BP can be positively affected by PC. Additionally, the correlation between BP and PC gives lessons to investors, they can store Bitcoin or consider it as an asset in the portfolio if the U.S. factionalism is fierce, in order to reduce the investment risks and enhance their returns. Also, they must pay attention to the Bitcoin bubbles and avoid blind speculation. This interaction also provides insights to the related authorities, they can prevent the large fluctuations in BP to ensure the stable development of the Bitcoin market, as well as reduce the uncertainty in the society to achieve the national stable growth. Furthermore, the existing studies mainly apply the full-sample test, which can only identify a constant Granger causality, but the time-varying interaction between BP and PC is ignored. Thus, we choose the bootstrap sub-sample rolling-window causality test to make the empirical results more comprehensive (Balcilar et al., 2010; Su et al., 2019; Qin et al., 2020; Su et al., 2020a, 2020b). Then, we can acquire the non-constant correlation between Bitcoin market and the U.S. political environment.

The remainder of this study is systematized as follows: Section 1 reports the related papers. Section 2 explains the theoretical model of BP and PC. Section 3 describes the empirical methods. Section 4 introduces the data. Section 5 reveals the empirical outcomes. Last Section summarizes the results and provides insights.

\section{Literature review}

The ability of Bitcoin to avoid risks has drawn great attentions among scholars, and the existing studies mainly solve this issue by considering the relationship between BP and uncertainty. Since PC can affect various fields (Cheng et al., 2016, 2018; Jiang \& Shi, 2018; Gupta et al., 2018a, 2018b; Azzimonti, 2019; Cai \& Wu, 2019; Su et al., 2020c), it may lead to high uncertainty in a country or region (Gøtzsche-Astrup, 2019). Bouri et al. (2017) find that Bitcoin can act as a hedge to avoid the global uncertainty which partly caused by high PC. Bouri et al. (2018) point out that Bitcoin can be considered as a safe-haven against global financial stress. Demir et al. (2018) evidence that economic policy uncertainty has predictive power on Bitcoin returns and Bitcoin can be viewed as an asset to hedge this uncertainty. Akhta- 
ruzzaman et al. (2019) indicate that the most effective hedge in a Bitcoin/industry (bond) portfolio is to short Utilities sector. Bouoiyour et al. (2019) reveal that Bitcoin can serve as a hedge, a safe haven and a diversifier for the uncertainty in the oil market, also it is an asset where investors may park their cash during the periods with high PC. Bouri and Gupta (2019) point out that Bitcoin has the ability to hedge uncertainty which partly caused by the rise in PC, and this uncertainty can predict BP more accurately. Chan et al. (2019) highlight that Bitcoin is an effective strong hedging asset for Euro STOXX, Nikkei, Shanghai A-Share, standard \& poor (S\&P) 500, and the Toronto Stock Exchange (TSX) Index under monthly data frequency. Fang et al. (2019) suggest that Bitcoin can act as a hedge under certain situations with global economic policy uncertainty. Kalyvas et al. (2019) ascertain that there is a negative association between economic uncertainty and the crash risk of BP, and investors can avoid this uncertainty by holding Bitcoin (also Colon et al., 2020). Neves (2020) indicates that Bitcoin can be used as a safe haven by the financial market during a worldwide crisis.

However, the view that Bitcoin has the ability to hedge risks does not always be supported. Klein et al. (2018) reveal that Bitcoin has a positive correlation with downward markets, indicating that there is no evidence can prove its stable hedging ability. Gozgor et al. (2019) underline that the trade policy uncertainty has a negative effect on Bitcoin returns, and the hedging ability of Bitcoin does not exist. Kliber et al. (2019) suggest that the ability to hedge risks depends on whether the trade is on the local Bitcoin exchanges or in a global one. Matkovskyy and Jalan (2019) find that risk-averse investors are more willing to move away from risky Bitcoin markets towards safer financial markets during the periods with crises. Shahzad et al. (2019) ascertain that the ability to avoid risks for stock market investments is time-varying, as well as differences across the stock market indices. Conlon and McGee (2020) refer to that Bitcoin does not act as a safe haven, instead declining in BP in lockstep with the Standard \& Poor's (S\&P) 500 as the crisis develops. Qin et al. (2020) suggest that Bitcoin cannot always be considered as a tool to avoid risks, indicating that there is no hedging ability to avoid the global economic policy uncertainty during a few periods. Shahzad et al. (2020) evidence that the hedging effectiveness of gold is greater than Bitcoin. Shaikh (2020) indicates that the economic policy uncertainty in the U.S. and Japan has a negative influence on the Bitcoin market, while there is a positive impact in China. Yen and Cheng (2020) highlight that a change in economic policy uncertainty of China affects cryptocurrency volatility, but it does not hold in the U.S., Japan, and Korea.

Most previous researches present a one-way impact of uncertainty on the Bitcoin market or vice versa, but hardly of them investigate the association between BP and PC. Thus, the interrelationship between the Bitcoin market and the U.S factionalism has not been analyzed in-depth, there is no study to solve the issue of whether Bitcoin is the winner after the U.S. factionalism. Furthermore, the previous studies cannot take the time-varying parameters in the empirical models into account, and the non-constant interaction between BP and PC is ignored. Therefore, this paper applies the bootstrap sub-sample rolling-window causality test (Balcilar et al., 2010; Su et al., 2019; Qin et al., 2020) to investigate the time-varying effect of PC to BP, which can answer the question of whether Bitcoin is the winner after the U.S. factionalism. Also, we can identify the role of the Bitcoin market in the U.S. political environment by exploring the non-stable impact from BP to PC. 


\section{Intertemporal capital asset pricing model of $B P$ and $P C$}

In order to explore the transmission mechanism between BP and PC, we consider the intertemporal capital asset pricing model (ICAPM) developed by Cifarelli and Paladino (2010). We presume Bitcoin market has two investors (informed and feedback investors), and the systematic risk is represented by PC. First, we consider the informed investors who take risk-return into account, and they will grasp the trend of BP by observing PC. Then, they determine their demand for Bitcoin as Eq. (1):

$$
i_{t}^{D}=\frac{E_{t-1}\left(\mathrm{BP}_{t}\right)-\mathrm{BP}^{f}}{\mu\left(\mathrm{PC}_{t}\right)},
$$

where $i_{t}^{D}$ is the share of Bitcoin stored by the informed investors. $\mu\left(\mathrm{PC}_{t}\right)>0$ and $\mu^{\prime}\left(\mathrm{PC}_{t}\right)>0$ indicate that this is a monotonically increasing function and all values are greater than 0 . $\mathrm{BP}^{f}$ is the price of Bitcoin without PC. $E_{t-1}\left(\mathrm{BP}_{t}\right)$ is the conditional expectation of BP. Suppose that the Bitcoin market only has informed investors, then $i_{t}^{D}=1$. Also, Eq. (1) can be rewritten as $E_{t-1}\left(\mathrm{BP}_{t}\right)=\mathrm{BP}^{f}+\mu\left(\mathrm{PC}_{t}\right)$, that is the capital asset pricing model (CAPM) which is developed by Sharpe (1964). It is obvious that the PC has a positive influence on BP. Then, we consider the feedback traders, who take the serial correlation of BP into account, and the ICAPM can be constructed. The share of Bitcoin stored by the feedback traders is $f_{t}^{D}=\theta \mathrm{BP}_{t-1}$ where $\theta>0$. Suppose that the Bitcoin market has these two kinds of investors, we have $i_{t}^{D}=1-f_{t}^{D}$, then Eq. (1) can be transformed to Eq. (2):

$$
E_{t-1}\left(\mathrm{BP}_{t}\right)=\mathrm{BP}^{f}+\mu\left(\mathrm{PC}_{t}\right)-\theta \mu\left(\mathrm{PC}_{t}\right) \mathrm{BP}_{t-1} .
$$

We can observe that the coefficient of $\mu\left(\mathrm{PC}_{t}\right)$ is $1-\theta \mathrm{BP}_{t-1}$, and this is a positive value since $\theta \mathrm{BP}_{t-1}=f_{t}^{D}<1$. Hence, $\mathrm{BP}$ can be positively affected by $\mathrm{PC}$, and high $\mathrm{PC}$ may drive $\mathrm{BP}$ to rise, in order to compensate for the losses and costs from factionalism. For instance, the presidential election in 2016 causes the conflicts between Democrats and Republicans to be fiercer, which leads PC to increase. During this period, investors are inclined to store assets (e.g., Bitcoin) with hedging capacity, driving BP to soar. Therefore, we can provide a hypothesis from the ICAPM, that is Bitcoin can be viewed as a tool to avoid uncertainty caused by high PC, it also can be viewed as the winner after the U.S. factionalism.

\section{Methodology}

\subsection{Bootstrap full-sample causality test}

If the standard normal distribution cannot be satisfied in the vector autoregression (VAR) model, the results of causality may be incorrect. Then, Shukur and Mantalos (1997) develop the residual-based bootstrap $(R B)$ method to improve the robustness of the Granger causality test. They underline that this method is suitable for the statistics with standard asymptotic distributions, also in the small time series. Also, Shukur and Mantalos (2000) propose the likelihood ratio $(L R)$ test, which is revised through the features of power and size. Thus, we perform the $R B$-based modified- $L R$ statistics to explore the interaction between BP and PC. Moreover, the fluctuations in PC may influence the value of the U.S. dollars (Su et al., 2020c), 
which also has certain impacts on BP since it is denominated in U.S. dollars (Dyhrberg, 2016; Baur et al., 2018; Qin et al., 2020). Thus, the correlation between BP and PC may be influenced by the U.S. dollar index (USDX). Additionally, the changes in the economic policy have certain effects on the association between BP and PC (Demir et al., 2018; Fang et al., 2019; Qin et al., 2020). Then, we choose USDX and U.S. economic policy uncertainty (EPU) as control variables in the VAR system as Eq. (3):

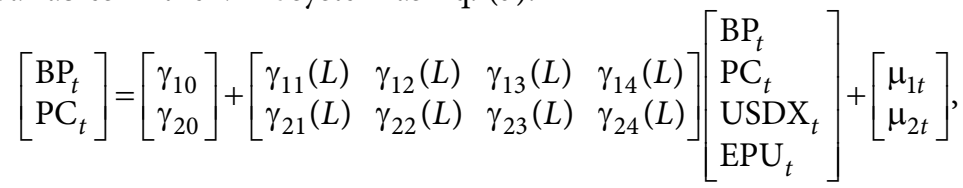

where $\mu_{t}=\left(\mu_{1 t}, \mu_{2 t}\right)^{\prime}$ is a white-noise process. $\gamma_{i j}(L)=\sum_{k=1}^{p} \gamma_{i j, k} L^{k}$, where $i=1,2 ; j=1,2,3,4$; $p$ is an optimal lag order; $L$ is a lag operator, and there is $L^{k} Z_{t}=Z_{t-k}$. The null hypothesis that PC can not affect BP, that is $\gamma_{12, k}=0$ can be rejected when PC is a Granger cause for $\mathrm{BP}$, and vice versa. Likewise, the null hypothesis that BP has no effect on PC $\left(\gamma_{21, k}=0\right)$ can also be examined.

\subsection{Parameter stability test}

The above test presumes that the parameters in the VAR system are constant, which is inconsistent with the practice. Thus, if the parameters are non-stable, applying the full-sample test is not appropriate. Thereby, we perform the parameter stability tests, containing Sup-F, Ave-F and Exp-F tests (Andrews, 1993; Andrews \& Ploberger, 1994) which can identify the structural mutations, as well as the $L_{c}$ statistics (Nyblom, 1989; Hanson, 1992) to verify whether the parameters follow a random walk process. Through these four tests, the non-stable interrelationship between BP and PC can be recognized if there exists parameter instability. Therefore, we should employ the sub-sample test to analyze the correlation between BP and PC.

\subsection{Bootstrap sub-sample rolling-window causality test}

This sub-sample method is developed by Balcilar et al. (2010), in order to separate the overall sample $S$ into small sections based on the rolling-window width $w$. The final of every section is $w, w+1, \ldots \ldots ., S$ and we can get $S-w+1$ sub-samples. Also, each one can get a result from the Granger causality test by performing the $R B$-based modified- $L R$ statistics. Then, we can obtain the outcomes of the sub-sample test as follows: $N_{b}^{-1} \sum_{k=1}^{p} \hat{\gamma}_{12, k}^{*}$ and $N_{b}^{-1} \sum_{k=1}^{p} \hat{\gamma}_{21, k}^{*}$ are the averages of the huge estimations, which reveal the effect from PC to BP and the influence of BP to PC, respectively; $N_{b}$ is the times of bootstrap iterations; $\hat{\gamma}_{12, k}^{*}$ and $\hat{\gamma}_{21, k}^{*}$ are the estimations through Eq. (3). This paper applies $90 \%$ confidence interval, and the related lower ( $5^{\text {th }}$ quantile) and upper ( $95^{\text {th }}$ quantile) limits (Balcilar et al., 2010; Qin et al., 2020).

\section{Data}

We choose the monthly data from 2010:M7 to 2020:M2, to investigate the interrelationship between Bitcoin price and partisan conflict, and further explore whether Bitcoin is the 
winner after the U.S. factionalism. In 2010, Obamacare, which is introduced by President Barack Obama, has caused the rise in the conflicts between Democrats and Republicans. We choose the partisan conflict (PC) index ${ }^{1}$, developed by Azzimonti (2014), to represent the U.S. factionalism. The PC index is calculated through recognizing words in the important U.S. newspapers ${ }^{2}$, which mainly contains two sets: political disagreement (e.g., "disagree", "deadlock" and "divided") and government (e.g., "White House", "party" and "partisan"). In addition, other terms related to PC (e.g., "divided party", "divided Congress" and "partisan divisions"), political debate (e.g., "fail to compromise") and the result of the partisan warfare (e.g., "gridlock" and "filibuster") are also taken into account. The higher PC index indicates that the level of U.S. factionalism is greater, and vice versa (Su et al., 2020c). Moreover, the first BitCoin platform, MT.Gox, is constructed in July 2010, making Bitcoin trading easier and also drawing more attention. We choose BitCoin price (BP) in U.S. dollars ${ }^{3}$, to reflect the Bitcoin market. Thereafter, BP rises sharply and Bitcoin can be viewed as an asset to avoid uncertainty in certain situations (Qin et al., 2020). The COVID-19 breaks out around the world in 2020, which causes global panic, leading to an increase in the demand for hedging asset (e.g., Bitcoin) and also BP. As Trump's response to this epidemic is weak which increases the dissatisfaction among political parties, then making PC rise ${ }^{4}$. Hence, there may be certain correlations between $\mathrm{BP}$ and $\mathrm{PC}$, which reveals the international digital market has a relation with the U.S. political environment. Figure 1 highlights the trends of BP and PC.

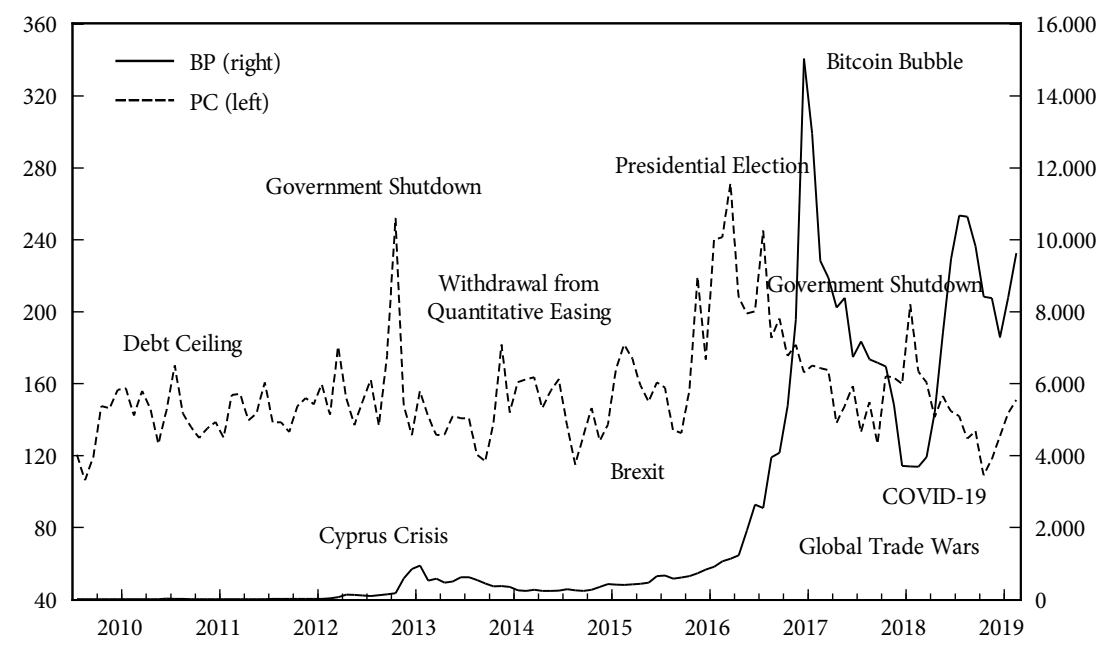

Figure 1. The trends of BP and PC

\footnotetext{
1 The partisan conflict index is taken from the Federal Reserve Bank of Philadelphia.

2 The important newspapers include Washington Post, New York Times, Los Angeles Times, Chicago Tribune and Wall Street Journal.

3 The Bitcoin price in U.S. dollars is taken from the Yahoo Finance.

4 Trump largely allows local officials to choose their own measures, but the Democratic presidential candidate Joe R. Biden advocates the implementation of restrictions on nationwide activities, in order to replace the selfadministered local policies.
} 
We can notice that BP and PC do not always move in the same directions, indicating that Bitcoin is not the winner after the U.S. factionalism during certain periods. Since the birth of Bitcoin, BP rises slightly as the lack of traders and formal exchanges, but PC fluctuates frequently by some significant events (e.g., Obamacare and debt ceiling). The U.S. government has closed for 16 days after failing to agree on Patient Protection and the Affordable Care Act in October 2013, which causes PC to rise sharply. This government shutdown and the Cyprus crisis in 2013 lead to the decline in investor sentiment, promoting them to invest hedging asset (e.g., digital currencies), which drives BP to rise. Then, BP and PC move in the same direction during this period, but this case can not be observed in 2014. Although the withdrawal from quantitative easing leads PC to increase, BP is in a downward trend. The main reason is that the value of the U.S. dollars has increased, decreasing the demand for Bitcoin and also BP. The Brexit in 2016 also affects U.S. factionalism, which causes the demand for Bitcoin to rise. Also, the unchanged Federal Funds Rate causes the U.S. dollars to depreciate, and BP further increases. The presidential election in 2016 leads PC to rise dramatically, and this upward trend has continued to 2017. During this time, BP has skyrocketed mainly due to the extensive investment of Bitcoin (especially by China, Japan and South Korea). After the presidential election, PC shows a declining trend with certain fluctuations, while BP is still in an upward trend. However, BP begins to fall sharply since the Bitcoin bubble bursts, while PC has gone through a decrease and then a rise. The government shut down 35 days in 2018, as funding for U.S.-Mexico border security could not be agreed, which drives PC to rise sharply, but BP does not increase during this time. The trade disputes initiated by the U.S., especially the Sino-U.S. trade frictions, lead to a rise in PC. In order to hedge the uncertainty caused by the rise in PC, the demand for Bitcoin increases which also drives BP to rise in the first half of 2019. However, the Bitcoin's ability to hedge risks of high PC caused by trade wars cannot be observed in 2018 and the second half of 2019. The outbreak of COVID-19 in 2020 makes the global panic, and investors are more willing to store Bitcoin to maintain their wealth, which causes BP to soar. Also, PC has increased due to the Democrats (e.g., Biden proposes to implement restrictions on nationwide activities) and Republicans (e.g., Trump promotes local officials to make their own measures) have different responses to this epidemic, which may threaten the public health and economic growth ${ }^{5}$. Thus, we can observe that Bitcoin is not always the winner after the U.S. factionalism. In addition, the changes in PC may affect the value of the U.S. dollars, such as the withdrawal from quantitative easing. Also, BP is denominated in U.S. dollars which may have certain effects on the Bitcoin market, such as the appreciation in U.S. dollars (e.g., Federal Reserve Board plans to raise interest rates) puts downward pressure on BP. Therefore, the interrelationship between BP and PC may be affected by the U.S. dollar index (USDX) ${ }^{6}$. Also, the U.S. economic policy uncertainty $(\mathrm{EPU})^{7}$ also has certain effects on the interaction between BP and PC, such as Bitcoin can be considered as a tool to avoid EPU and the changes in economic policies may cause political parties to the conflict. Then, we choose USDX and EPU as control variables in

\footnotetext{
${ }^{5}$ Another example is that the Los Angeles Mayor Eric Garcetti (Democrat) has ordered the closure of this city with a population of nearly 4 million. However, the Governor Tate Reeves (Republican) in Mississippi, which has a population of nearly 3 million, has allowed most enterprises to continue business.

6 The U.S. dollar index is taken from the Federal Reserve Board.

7 The U.S. economic policy uncertainty is taken from the Economic Policy Uncertainty Database.
} 
the VAR system. In general, the correlation between the Bitcoin market and U.S. factionalism is time-varying and also influenced by the value of the dollar.

Table 1 evidences the descriptive statistics. The averages of BP, PC, USDX and EPU are 2273.347, 154.871, 88.804 and 145.095, respectively. BP, PC and EPU are right-skewed distributions due to the positive skewness. The kurtoses of BP, PC and EPU are greater than 3 , hence, these three variables satisfy the leptokurtic distributions, which reveals a much higher peak around the mean value. In addition, the Jarque-Bera index indicates that the distributions of BP, PC, USDX and EPU are non-normal at the $1 \%$ level. Thus, applying the traditional Granger causality tests is not suitable in this paper. We use the $R B$ method to discuss these three variables and perform the bootstrap sub-sample rolling-window test to investigate the time-varying correlation between BP and PC under the control of USDX and EPU. To prevent the potential heteroscedasticity and possible instability, we take the natural logarithms and first differences of BP, PC, USDX and EPU.

Table 1. Descriptive statistics for BP, PC, USDX and EPU

\begin{tabular}{|l|c|c|c|c|}
\hline & BP & PC & USDX & EPU \\
\hline Observations & 116 & 116 & 116 & 116 \\
\hline Mean & 2273.347 & 154.871 & 88.804 & 145.095 \\
\hline Median & 429.108 & 148.275 & 92.039 & 137.850 \\
\hline Maximum & 15034.530 & 271.290 & 102.350 & 284.136 \\
\hline Minimum & 0.062 & 106.260 & 73.030 & 63.877 \\
\hline Standard Deviation & 3509.785 & 28.985 & 8.569 & 46.520 \\
\hline Skewness & 1.564 & 1.648 & -0.177 & 0.829 \\
\hline Kurtosis & 4.369 & 6.487 & 1.456 & 3.432 \\
\hline Jarque-Bera & $56.322^{* * *}$ & $111.303^{* * *}$ & $12.120^{* * *}$ & $14.190^{* * *}$ \\
\hline
\end{tabular}

Note: ${ }^{* * *}$ denotes significance at the $1 \%$ level.

\section{Empirical results}

Based on the VAR system as Eq. (3), we can test the full-sample causality between BP and PC. According to the Schwarz Information Criterion (SIC), we select 3 as the optimal lag order. The outcomes of the full-sample test are reported in Table 2. We can observe that there is no significant correlation between $\mathrm{BP}$ and $\mathrm{PC}$, indicating that $\mathrm{PC}$ does not affect $\mathrm{BP}$, and vice versa. These results are not supported by the existing studies (Bouri et al., 2017; Bouoiyour et al., 2019; Bouri \& Gupta, 2019), as well as the hypothesis of the ICAPM which highlights that BP can be positively affected by PC.

Table 2. Full-sample Granger causality tests

\begin{tabular}{|c|c|c|c|c|}
\hline \multirow{2}{*}{ Tests } & \multicolumn{2}{|c|}{$\mathrm{H}_{0}$ : PC does not Granger cause BP } & \multicolumn{2}{c|}{$\mathrm{H}_{0}$ : BP does not Granger cause PC } \\
\cline { 2 - 5 } & Statistics & $p$-value & Statistics & $p$-value \\
\hline Bootstrap $L R$ test & 4.921 & 0.220 & 3.967 & 0.260 \\
\hline
\end{tabular}

Note: We calculate $p$-value using 10,000 bootstrap repetitions. 
The full-sample estimation in Eq. (3) presumes that there is no time-varying parameter, and only one Granger causality exists in the overall sample. Yet, this assumption does not hold when the variables and the VAR models have structural mutations, and there are timevarying correlations between BP and PC (Balcilar \& Ozdemir, 2013; Qin et al., 2020). Hence, this paper performs Sup-F, Ave-F and Exp-F tests (Andrews, 1993; Andrews \& Ploberger, 1994), as well as the $L_{c}$ statistics (Nyblom, 1989; Hanson, 1992) to capture this non-stable feature. Table 3 reports the outcomes of the above tests.

Table 3. The results of parameter stability test

\begin{tabular}{|l|c|c|c|c|c|c|}
\hline \multirow{2}{*}{ Tests } & \multicolumn{2}{|c|}{ BP } & \multicolumn{2}{c|}{ PC } & \multicolumn{2}{c|}{ VAR system } \\
\cline { 2 - 7 } & Statistics & $p$-value & Statistics & $p$-value & Statistics & $p$-value \\
\hline Sup- $F$ & $31.888^{* * *}$ & 0.000 & $30.421^{* * *}$ & 0.000 & $29.407^{* * *}$ & 0.001 \\
\hline Ave-F & $13.349^{* * *}$ & 0.000 & $8.753^{* *}$ & 0.007 & $12.131^{* *}$ & 0.015 \\
\hline Exp-F & $12.344^{* * *}$ & 0.000 & $10.860^{* * *}$ & 0.000 & $10.877^{* * *}$ & 0.002 \\
\hline$L_{c}$ & & & & & $2.579^{* * *}$ & 0.005 \\
\hline
\end{tabular}

Notes: We calculate $p$-value using 10,000 bootstrap repetitions.

${ }^{* * *}$ and ${ }^{* *}$ denote significance at the $1 \%$ and $5 \%$ levels, respectively.

The Sup-F and Exp-F tests reveal that the parameter instability exists in BP, PC and VAR system at the $1 \%$ level. And Ave-F test also indicates that the constancy does not hold in BP and PC at the $1 \%$ level, while the VAR system at the $5 \%$ level. Additionally, the $L_{c}$ statistics test highlights that the parameters in the VAR system do not follow a random walk process. Hence, by summing up the above results, we can ascertain that BP and PC have a non-constant interrelationship. However, the full-sample test catches a stable Granger causality, which has proven to be inappropriate for this paper. Therefore, we employ the sub-sample test to explore the non-stable correlation between BP and PC. Yet the choice of the rolling-window width is perplexed, the small width can not ensure the accuracy, while a large one may reduce the frequency of scrolls. Then, Pesaran and Timmermann (2005) underline that this width cannot be less than 20 in the sub-sample test. Thereby, we choose the rolling-window width is 24-months ${ }^{8}$, ensuring the robustness of the empirical results (Qin et al., 2020). Then, we can verify whether the rise in PC has an influence on $\mathrm{BP}$, and vice versa. Also, this influence is positive or negative can also be obtained.

Figures 2 and 3 highlight the $p$-values and the orientations of the effects of PC on BP. The alternative hypothesis of PC Granger causes BP can be accepted during the periods of 2016:M11-2017:M3, 2018:M8-2018:M11 and 2020:M1-2020:M2 at the 10\% level, and both positive (2016:M11-2017:M3 and 2020:M1-2020:M2) and negative (2018:M8-2018:M11) effects exist from PC to BP.

The positive effects of PC on BP can verify that Bitcoin is the winner after the U.S. factionalism. The $58^{\text {th }}$ U.S. Presidential Election is held on November 8, 2016. After voting in

\footnotetext{
8 To test the robustness of the sub-sample outcomes, we select the widths of 20-, 28- and 32- months to conduct the analysis, and the outcomes are unanimous with 24 -months.
} 


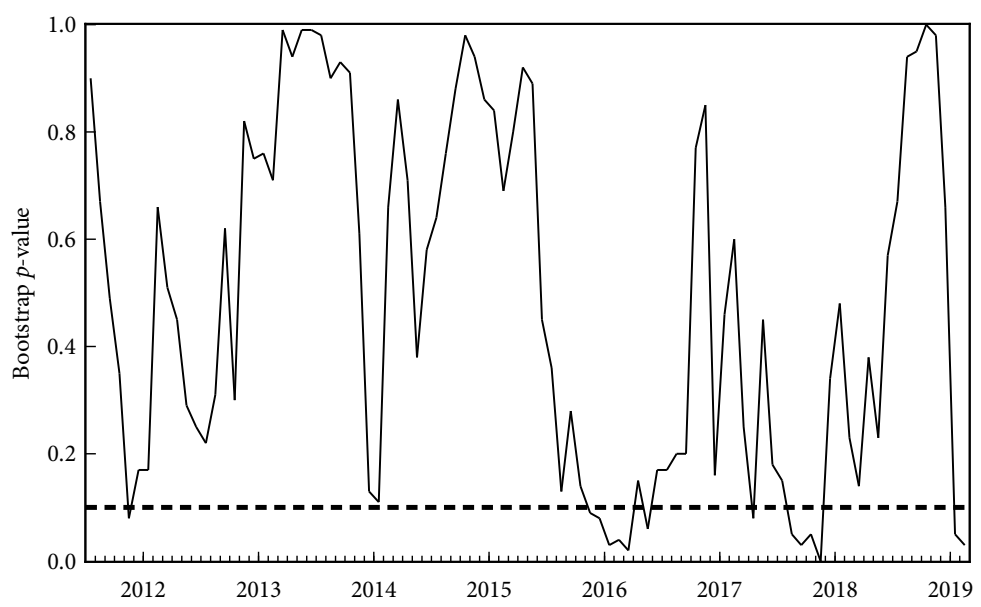

Figure 2. Bootstrap $p$-values of rolling test statistic testing the null hypothesis that PC does not Granger cause BP

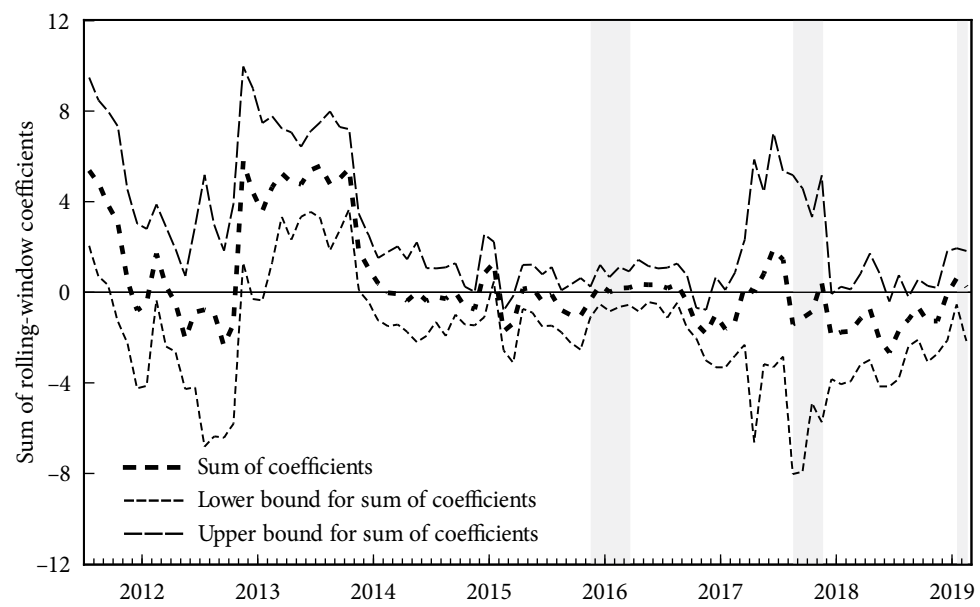

Figure 3. Bootstrap estimates of the sum of the rolling-window coefficients for the impact of PC on BP

each state, Trump is elected and the inauguration ceremony is held on January 20, 2017. In this presidential election, the conflicts between Democrats and Republicans are extremely fierce, such as some major scandals (e.g., Hillary's email controversy, Trump's sex scandals) are exposed. Since then, there are new policies promulgated by the Trump administration, such as abolishing Obamacare, withdrawing from the Trans-Pacific Partnership (TPP) Agreement (Gleeson et al., 2018) and building walls at the U.S.-Mexico border, which can not be unified among Democrats and Republicans. Thereby, PC increases sharply during the period of 2016:M11-2017:M3, and there are three ways to explain its positive influence on BP. Firstly, the rise in PC causes the investor sentiment and consumer confidence to decline, which makes them inclined to store assets (e.g., Bitcoin) with hedging capacity (Jiang et al., 2020; Qin et al., 2020). Then, the demand for Bitcoin increases, driving BP to soar. 
Secondly, the actions taken by the Trump administration have led to high uncertainty in the society (Pham et al., 2018; Regilme, 2019), which causes to the insufficient market expectations for the U.S. dollars. Then, the public may reduce their U.S. dollars holdings, and store more Bitcoin whose price is on the rise, thereby driving BP to further increase. Thirdly, the presidential election has made cryptocurrencies wider recognized. For instance, Rand Paul, a Kentucky senator and one of the candidates for the presidential election, has accepted Bitcoin as a campaign contribution. Also, Hillary supports the underlying technology of Bitcoin. All of these can help the Bitcoin market to be more attractive, which increases its demand and price. Furthermore, as the continuous rise in BP, there are extensive investments in Bitcoin market around the world (especially by China, Japan and South Korea), driving BP to skyrocket (Li et al., 2018; Xiong et al., 2019). Therefore, we can conclude that PC can positively affect BP during the period of 2016:M11-2017:M3.

The COVID-19 has broken out in 2020, which has spread around the world. The responses and measures of Trump administration adopted to this epidemic can not effectively curb its spread, then the dissatisfaction among political parties has heated up sharply, driving PC to rise. In addition, the U.S. can not control the outbreak of the influenza B virus, making it be the worst one in 40 years. Also, there are geopolitical events happened, such as assassinating Qasem Soleimani ${ }^{9}$ with the drone and hitting U.S. military Iraqi location by Iranian rocket. All of these incidents have further caused PC to increase during the period of 2020:M1-2020:M2, and its positive effect on BP can be explained through four reasons. Firstly, the high PC makes investors more willing to hold Bitcoin, in order to avoid losses caused by the factionalism and maintain their wealth, which drives BP to rise. Secondly, the geopolitical events can not only lead PC to increase but also bring more geopolitical risks (Caldara \& Iacoviello, 2017; Clance et al., 2018; Su et al., 2019, 2020c). Then, in order to hedge these risks, the demand for Bitcoin has increased, and BP moves in the same direction as PC. Thirdly, with the large-scale spread of COVID-19, PC may further increase, and the public is pessimistic about the future epidemic prevention and control. Then, their negative sentiments cause to the increase in the investment in relatively safe assets, such as Bitcoin. Fourth, the COVID-19 also causes the prices of several assets (e.g., oil, U.S. stock, commodities) to fall, which reduces the demand for such assets. In turn, BP is in an upward trend during this period, leading to an increase in the demand for Bitcoin, which further drives $\mathrm{BP}$ to rise. Hence, the positive effect of PC on BP during the period of 2020:M1-2020:M2 can be proved.

However, the statement of Bitcoin is the winner after the U.S. factionalism can not be approved by the negative influence. The U.S. imposes tariffs on goods which are imported from China, then the U.S. Senate restrains Trump's tariff power with an overwhelming number of votes. This restrictive measure and the trade frictions with China have undoubtedly caused PC to increase. In addition, the plan of the U.S.-Mexico border wall proposed by Trump meets many objections, which further worsens the factionalism. Hence, there is a rise in PC covering the period of 2018:M8-2018:M11, but BP does not move in the same direction which can be explained through two aspects. On the one hand, since the Bitcoin bubble

\footnotetext{
${ }^{9}$ Qasem Soleimani, the Brigadier of the Holy City Brigade of the Islamic Revolutionary Guard of Iran, was killed in the attacks by three U.S. forces near the Baghdad International Airport in the Iraqi capital.
} 
bursts, BP falls sharply (Li et al., 2018; Xiong et al., 2019). Then, the investor sentiment is low and quickly withdraw from the Bitcoin market, causing BP to further plummet (Qin et al., 2020). Although PC is high, Bitcoin is not considered as an asset with hedging ability during this period, thus the demand for Bitcoin and BP do not move in the same direction as PC. On the other hand, the trade frictions drive PC to rise, but the U.S. dollars appreciate at this time partly caused by the improvement of the U.S. economy and the Federal Reserve Board raises interest rates. Since BP is denominated in U.S. dollars, there is a negative relationship between BP and the value of the U.S. dollars (Dyhrberg, 2016; Baur et al., 2018). Then, the appreciation of the U.S. dollars causes BP to decrease continually. Thus, we can prove that PC has a negative effect on BP during the period of 2018:M8-2018:M11, this result is inconsistent with the ICAPM which highlights the positive influence from PC to BP.

Figures 4 and 5 underline the $p$-values and the orientations of the effects of BP no PC. The alternative presumption of BP Granger causes PC can be accepted during the periods of 2018:M11-2019:M1 and 2019:M10-2019:M11 at the 10\% level. There are negative effects from BP to PC during these two periods, indicating that the U.S. political situation can be reflected by the Bitcoin market.

Since the burst of the Bitcoin bubble and the relatively high value of the U.S. dollar, BP is in a downturn trend during the period of 2018:M11-2019:M1 (Baur et al., 2018; Li et al., 2018; Xiong et al., 2019; Qin et al., 2020). Also, the uncertainty of the Bitcoin cash (BCH) permanent divergence is also one of the main reasons for the plunge in BP. However, PC has significantly increased partly due to the trade frictions with China. Although the heads of state of China and the U.S. have reached a consensus to stop increasing new tariffs on December 1, 2018, the government shutdown from December 22, 2018, to January 25, 2019, leads to a sharp rise in PC (Su et al., 2020c). Due to the difficulty of reconciling the differences in the budget for the construction of the U.S.-Mexico border wall, this government shutdown lasts 35 days, setting a record for the longest one. Thereby, PC has still increased, while there is a decline in BP. During this time, Bitcoin cannot be considered as an asset to

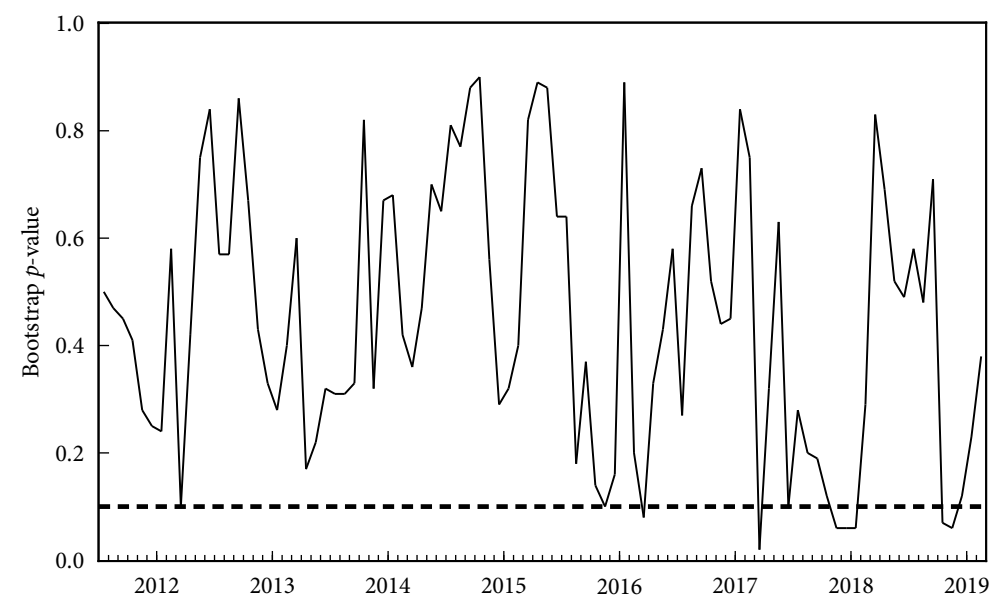

Figure 4. Bootstrap $p$-values of rolling test statistic testing the null hypothesis that $\mathrm{BP}$ does not Granger cause PC 


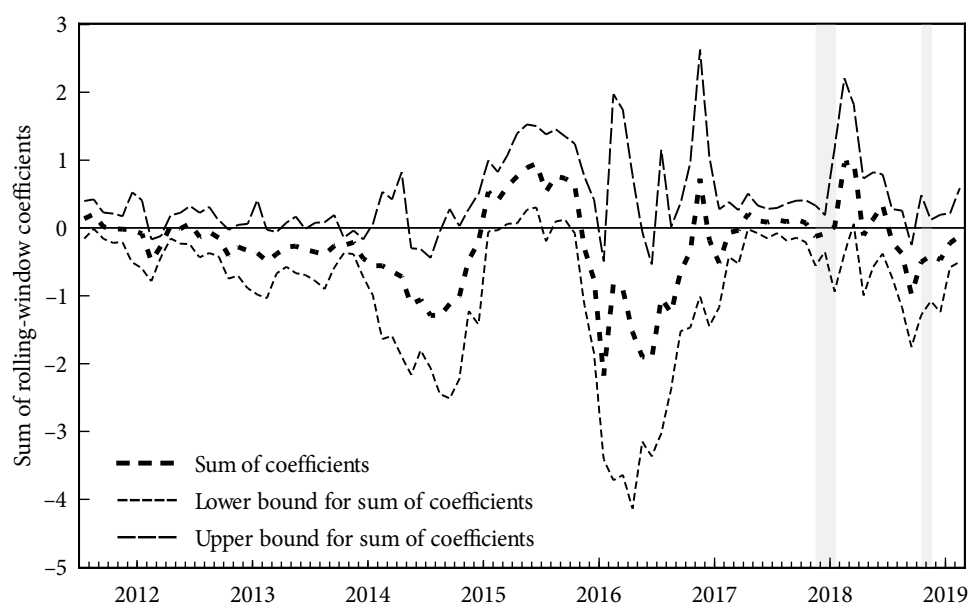

Figure 5. Bootstrap estimates of the sum of the rolling-window coefficients for the impact of $\mathrm{BP}$ on $\mathrm{PC}$

avoid the risks caused by high PC, as its price continually falls. Then, the public pessimism cannot be resolved by holding Bitcoin, and it is difficult to improve the stability of the U.S. society, which may further intensify the conflicts between political parties. Thus, the negative influence of BP on PC during the period of 2018:M11-2019:M1 can be verified.

Although BP rises to nearly $\$ 14,000$ in the first half of 2019 , it does not continue to increase, and BP plummets during the period of 2019:M10-2019:M11. There are three reasons to explain the decline in BP. Firstly, the Bakkt ${ }^{10}$ futures perform is worse than expected, which reduces the investor confidence in the digital currency market. Then, the demand for Bitcoin decreases, causing BP to fall. Secondly, Google has made significant progress in quantum computing, which may threaten the development of the Bitcoin market. Thirdly, the U.S. Securities and Exchange Commission (SEC) has postponed rulings on the applications for three cryptocurrency exchange-traded funds (ETF). This change in the attitude of regulators makes the prospects of the Bitcoin market worse than expected, causing to the decline in Bitcoin holdings, as well as BP. Since BP is in a downturn trend, the CEO of Brian Kelly Capital Management (BKCM) has stated that $\$ 9,000$ is a major support level, and if BP falls below this level, there may be a large-scale selling. Thereby, BP plummets during this time, while PC is still at a relatively high level. In 2019, the U.S. has officially withdrawn from the Intermediate-Range Nuclear Forces (INF) Treaty, the Sino-U.S. trade frictions continue, and Trump has been impeached for two clauses (abusing his powers and preventing Congressional investigations). All of these events drive PC to soar, but the decline in BP makes Bitcoin can not be viewed as a hedging asset. Then, the public panic cannot be comforted by the Bitcoin market, and it is not beneficial for the healthy development of the society, which may aggravate the factionalism. Hence, we can conclude that BP has a negative influence on PC during the period of 2019:M10-2019:M11.

\footnotetext{
${ }^{10}$ Bakkt is a platform for buying, selling, storing and using digital currencies, created by the New York Stock Exchange parent company Intercontinental Exchange (ICE) in August 2018.
} 
In general, the bootstrap full-sample test reveals that no mutual influence between BP and PC exists, which is not robust due to the parameters are presumed constant in the VAR models. In order to examine whether there is a non-stable relationship between these two variables, we apply the parameter stability tests, and the results ascertain that BP, PC and the VAR system have structural mutations. Thus, we employ the sub-sample test to analyze the non-constant correlation between BP and PC, as well as consider USDX and EPU as control variables. The empirical results point out that the interrelationship between these two variables has only been significant in the last 4 years. Firstly, both positive and negative effects exist from PC to BP. The positive influence suggests that BP will rise if the PC is higher, indicating that Bitcoin can be viewed as a tool to avoid uncertainty caused by the conflicts among U.S. political parties. Thereby, Bitcoin is the winner after the U.S. factionalism, but this view cannot be held during the period with negative influence. The main reason for this negative effect from PC to BP is the burst of the Bitcoin bubble, then BP falls sharply even if the U.S. factionalism is fierce. Secondly, these results are not supported by the ICAPM, which indicates that there is a positive influence from PC to BP. Thirdly, there is a negative impact of BP on PC, which highlights that the U.S. political environment can be reflected by the Bitcoin market.

\section{Conclusions}

This paper investigates the mutual influence between the Bitcoin market and the U.S. political situation, and further, verify whether Bitcoin is the winner after the U.S. factionalism. We employ the full- and sub-sample tests to analyze the interaction between BP and PC. The empirical results indicate that both positive and negative influences exist from $\mathrm{PC}$ to $\mathrm{BP}$. The positive effect reveals that Bitcoin can be viewed as a tool to avoid the uncertainty of high $\mathrm{PC}$, due to $\mathrm{BP}$ will increase under the environment with high factionalism. Also, we can observe that Bitcoin is the winner after the U.S. factionalism. However, this view cannot be supported by the negative influence of $\mathrm{PC}$ on $\mathrm{BP}$, which mainly caused by the plummet in BP during the period of the burst of Bitcoin bubble, even if the U.S. factionalism is fierce. These results are not consistent with the ICAPM, which highlights that BP is positively affected by PC, and Bitcoin can be viewed as a tool to avoid uncertainty caused by fierce factionalism. In turn, there is a negative influence of $\mathrm{BP}$ on PC, indicating that the Bitcoin market should be taken into account when analyzing the U.S. political situation. Through exploring the time-varying correlation between $\mathrm{BP}$ and $\mathrm{PC}$, we can evidence that Bitcoin is not always the winner after the U.S. factionalism, due to its ability to avoid risks caused by PC only exists in several periods.

Understanding the hedging ability of Bitcoin and the U.S. political environment, as well as the interrelationship between BP and PC can give lessons to both investors and related authorities. Firstly, PC positively affects BP during a few periods. Then, investors can grasp the trend of future BP by completely considering the U.S. political situation. They can store Bitcoin or view it as an asset in the portfolio if the U.S. factionalism is fierce, in order to reduce the investment risks and enhance their returns. The related authorities also can predict BP through the fluctuations in PC. Then, they can prevent large fluctuations in BP, which 
may be harmful to public confidence and market stability. Secondly, due to the burst of the Bitcoin bubble, BP is negatively affected by PC. During the periods with Bitcoin bubbles, investors should withdraw from this market and avoid the blind speculation, in order to reduce the investment losses and maintain their wealth. The related authorities should prevent the large-scale panic due to the bubble bursts. Also, they should improve the encryption technology and enhance network security, as well as reinforce the supervision, to draw more traders and ensure the stable development of the Bitcoin market. Thirdly, BP has certain influences on PC during several periods, which underlines that the Bitcoin market can be an effective leading factor of the U.S. political environment. Then, the related authorities can implement policies to decrease the negative effects caused by the U.S. factionalism. Also, they must take measures to raise the public confidence in government, to avoid the further panic due to the high PC. Thereby, they can reduce the uncertainty in society and create a harmonious environment, which is beneficial to the U.S. steady growth.

\section{Funding}

This research is partly supported by the National Social Science Fund of China (20BJY021).

\section{References}

Akhtaruzzaman, M., Sensoy, A., \& Corbet, S. (2019). The influence of Bitcoin on portfolio diversification and design. Finance Research Letters, 37, 101344. https://doi.org/10.1016/j.frl.2019.101344

Andrews, D. W. K. (1993). Tests for parameter instability and structural change with unknown change point. Econometrica, 61(4), 821-856. https://doi.org/10.2307/2951764

Andrews, D. W. K., \& Ploberger, W. (1994). Optimal tests when a nuisance parameter is present only under the alternative. Econometrica, 62(6), 1383-1414. https://doi.org/10.2307/2951753

Azzimonti, M. (2014). Partisan conflict (Working Paper No. 14-19). FRB of Philadelphia. https://doi.org/10.2139/ssrn.2457406

Azzimonti, M. (2019). Does partisan conflict deter FDI inflows to the US? Journal of International Economics, 120, 162-178. https://doi.org/10.1016/j.jinteco.2019.06.001

Balcilar, M., \& Ozdemir, Z. A. (2013). The export-output growth nexus in Japan: A bootstrap rolling window approach. Empirical Economics, 44, 639-660. https://doi.org/10.1007/s00181-012-0562-8

Balcilar, M., Ozdemir, Z. A., \& Arslanturk, Y. (2010). Economic growth and energy consumption causal nexus viewed through a bootstrap rolling window. Energy Economics, 32(6), 1398-1410. https://doi.org/10.1016/j.eneco.2010.05.015

Bartsch, Z. (2019). Economic policy uncertainty and dollar-pound exchange rate return volatility. Journal of International Money and Finance, 98, 102067. https://doi.org/10.1016/j.jimonfin.2019.102067

Baur, D. G., Dimpfl, T., \& Kuck, K. (2018). Bitcoin, gold and the US dollar - A replication and extension. Finance Research Letters, 25, 103-110. https://doi.org/10.1016/j.frl.2017.10.012

Bouoiyour, J., Selmi, R., \& Wohar, M. E. (2019). Safe havens in the face of presidential election uncertainty: A comparison between Bitcoin, oil and precious metals. Applied Economics, 51(57), 60766088. https://doi.org/10.1080/00036846.2019.1645289

Bouri, E., \& Gupta, R. (2019). Predicting Bitcoin returns: Comparing the roles of newspaper- and internet search-based measures of uncertainty. Finance Research Letters, 101398.

https://doi.org/10.1016/j.frl.2019.101398 
Bouri, E., Gupta, R., Lau, C. K. M., Roubaud, D., \& Wang, S. X. (2018). Bitcoin and global financial stress: A copula-based approach to dependence and causality in the quantiles. The Quarterly Review of Economics and Finance, 69, 297-307. https://doi.org/10.1016/j.qref.2018.04.003

Bouri, E., Gupta, R., Tiwar, A. K., \& Roubaud, D. (2017). Does Bitcoin hedge global uncertainty? Evidence from wavelet-based quantile-in-quantile regressions. Finance Research Letters, 23, 87-95. https://doi.org/10.1016/j.frl.2017.02.009

Cai, Y. F., \& Wu, Y. R. (2019). Time-varied causality between US partisan conflict shock and crude oil return. Energy Economics, 84, 104512. https://doi.org/10.1016/j.eneco.2019.104512

Caldara, D., \& Iacoviello, M. (2017). Measuring geopolitical risk (International Finance Discussion Papers No. 1222). Board of Governors of the Federal Reserve System. https://doi.org/10.17016/IFDP.2018.1222

Chan, W. G., Le, M., \& Wu, Y. W. (2019). Holding Bitcoin longer: The dynamic hedging abilities of Bitcoin. The Quarterly Review of Economics and Finance, 71, 107-113. https://doi.org/10.1016/j.qref.2018.07.004

Cheng, C. G. J., Chiu, C. W., Hankins, W. B., \& Stone, A. (2018). Partisan conflict, policy uncertainty and aggregate corporate cash holdings. Journal of Macroeconomics, 58, 78-90. https://doi.org/10.1016/j.jmacro.2018.08.010

Cheng, C. H. J., Hankins, W. B., \& Chiu, C. W. (2016). Does US partisan conflict matter for the Euro area? Economics Letters, 138, 64-67. https://doi.org/10.1016/j.econlet.2015.11.030

Cifarelli, G., \& Paladino, G. (2010). Oil price dynamics and speculation: A multivariate financial approach. Energy Economics, 32(2), 363-372. https://doi.org/10.1016/j.eneco.2009.08.014

Clance, M. W., Gupta, R., \& Wohar, M. E. (2018). Geopolitical risks and recessions in a panel of advanced economies: Evidence from over a century of data. University of Pretoria, Department of Economics. https://repository.up.ac.za/bitstream/handle/2263/68295/Clance_Geopolitical_2019. pdf? sequence $=1$ \&isAllowed $=y$

Colon, F., Kim, C., Kim, H., \& Kim, W. (2020). The effect of political and economic uncertainty on the cryptocurrency market. Finance Research Letters, 101621 (in Press). https://doi.org/10.1016/j.frl.2020.101621

Conlon, T., \& McGee, R. (2020). Safe haven or risky hazard? Bitcoin during the Covid-19 bear market. Finance Research Letters, 35, 101607. https://doi.org/10.1016/j.frl.2020.101607

Demir, E., Gozgor, G., Lau, C. K. M., \& Vigne, S. A. (2018). Does economic policy uncertainty predict the Bitcoin returns? An empirical investigation. Finance Research Letters, 26, 145-149. https://doi.org/10.1016/j.frl.2018.01.005

Dyhrberg, A. H. (2016). Bitcoin, gold and the dollar - A GARCH volatility analysis. Finance Research Letters, 16, 85-92. https://doi.org/10.1016/j.frl.2015.10.008

Elwell, C. K., Murphy, M. M., \& Seitzinger, M. V. (2013). Bitcoin: Questions, answers, and analysis of legal issues (Congressional Research Service Report).

Fang, L., Bouri, E., Gupta, R., \& Roubaud, D. (2019). Does global economic uncertainty matter for the volatility and hedging effectiveness of Bitcoin? International Review of Financial Analysis, 61, 29-36. https://doi.org/10.1016/j.irfa.2018.12.010

Gleeson, D., Lexchin, J., Lopert, R., \& Kilic, B. (2018). The Trans Pacific Partnership Agreement, intellectual property and medicines: Differential Outcomes for developed and developing countries. Global Social Policy, 18(1), 7-27. https://doi.org/10.1177/1468018117734153

Gøtzsche-Astrup, O. (2019). Personality moderates the relationship between uncertainty and political violence: Evidence from two large U.S. samples. Personality and Individual Differences, 139, 102-109. https://doi.org/10.1016/j.paid.2018.11.006

Gozgor, G., Tiwari, A. K., Demir, E., \& Akron, S. (2019). The relationship between Bitcoin returns and trade policy uncertainty. Finance Research Letters, 29, 75-82.

https://doi.org/10.1016/j.frl.2019.03.016 
Gupta, R., Lau, C. K. M., Miller, S. M., \& Wohar, M. (2017). U.S. fiscal policy and asset prices: The role of partisan conflict. International Review of Finance, 19(4), 851-862. https://doi.org/10.1111/irfi.12188

Gupta, R., Mwamba, J. W. M., \& Wohar, M. E. (2018b). The role of partisan conflict in forecasting the U.S. equity premium: A nonparametric approach. Finance Research Letters, 25, 131-136. https://doi.org/10.1016/j.frl.2017.10.023

Gupta, R., Pierdzioch, C., Selmi, R., \& Wohar, M. E. (2018a). Does partisan conflict predict a reduction in US stock market (realized) volatility? Evidence from a quantile-on-quantile regression model. The North American Journal of Economics and Finance, 43, 87-96. https://doi.org/10.1016/j.najef.2017.10.006

Hanson, B. E. (1992). Tests for parameter instability in regressions with I(1) processes. Journal of Business and Economic Statistics, 20(1), 45-59. https://doi.org/10.1198/073500102753410381

Jiang, X. D., \& Shi, Y. L. (2018). Does US partisan conflict affect US-China bilateral trade? International Review of Economics \& Finance. https://doi.org/10.2139/ssrn.3122322

Jiang, Y., Ren, Y. S., Ma, C. Q., Liu, J. L., \& Sharp, B. (2020). Does the price of strategic commodities respond to U.S. partisan conflict? Resources Policy, 66, 101617. https://doi.org/10.1016/j.resourpol.2020.101617

Kalyvas, A., Papakyriakou, P., Sakkas, A., \& Urquhart, A. (2019). What drives Bitcoin's price crash risk? Economics Letters, 191, 108777. https://doi.org/10.1016/j.econlet.2019.108777

Klein, T., Thu, H. P., \& Walther, T. (2018). Bitcoin is not the New Gold - A comparison of volatility, correlation, and portfolio performance. International Review of Financial Analysis, 59, 105-116. https://doi.org/10.1016/j.irfa.2018.07.010

Kliber, A., Marszałek, P., Musiałkowska, I., \& Świerczyńska, K. (2019). Bitcoin: Safe haven, hedge or diversifier? Perception of bitcoin in the context of a country's economic situation - A stochastic volatility approach. Physica A: Statistical Mechanics and its Applications, 524, 246-257. https://doi.org/10.1016/j.physa.2019.04.145

Li, Z. Z., Tao, R., Su, C. W., \& Lobont, O. R. (2018). Does Bitcoin bubble burst? Quality \& Quantity, 53(2), 1-15. https://doi.org/10.1007/s11135-018-0728-3

Luther, W. J., \& Salter, A. W. (2017). Bitcoin and the bailout. Quarterly Review of Economics \& Finance, 66, 50-56. https://doi.org/10.1016/j.qref.2017.01.009

Mamun, M. A., Uddin, G. S., Suleman, M. T., \& Kang, S. H. (2020). Geopolitical risk, uncertainty and Bitcoin investment. Physica A: Statistical Mechanics and its Applications, 54, 123107. https://doi.org/10.1016/j.physa.2019.123107

Matkovskyy, R., \& Jalan, A. (2019). From financial markets to Bitcoin markets: A fresh look at the contagion effect. Finance Research Letters, 31, 93-97. https://doi.org/10.1016/j.frl.2019.04.007

Neves, R. H. D. (2020). Bitcoin pricing: impact of attractiveness variable. Financial Innovation, 6(1), 1-18. https://doi.org/10.1186/s40854-020-00176-3

Nyblom, J. (1989). Testing for the constancy of parameters over time. Journal of the American Statistical Association, 84(405), 223-230. https://doi.org/10.1080/01621459.1989.10478759

Pesaran, M. H., \& Timmermann, A. (2005). Small sample properties of forecasts from autoregressive models under structural breaks. Journal of Econometrics, 129(1-2), 183-217. https://doi.org/10.1016/j.jeconom.2004.09.007

Pham, H. N. A., Ramiah, V., Moosa, N., Huynh, T., \& Pham, N. (2018). The financial effects of Trumpism. Economic Modelling, 74, 264-274. https://doi.org/10.1016/j.econmod.2018.05.020

Pyo, S., \& Lee, J. (2019). Do FOMC and macroeconomic announcements affect Bitcoin prices? Finance Research Letters, 37, 101386. https://doi.org/10.1016/j.frl.2019.101386

Qin, M., Su, C. W., \& Tao, R. (2020). BitCoin: A new basket for eggs? Economic Modelling (in Press). https://doi.org/10.1016/j.econmod.2020.02.031 
Regilme, S. S. F. (2019). The decline of American power and Donald Trump: Reflections on human rights, neoliberalism, and the world order. Geoforum, 102, 157-166.

https://doi.org/10.1016/j.geoforum.2019.04.010

Ron, J., David, M., Charles, P., \& Jones, K. (2018). Geographies of Brexit and its aftermath: Voting in England at the 2016 referendum and the 2017 general election. Space \& Polity, 22(2), 162-187. https://doi.org/10.1080/13562576.2018.1486349

Shahzad, S. J. H., Bouri, E., Roubaud, D., \& Kristoufek, L. (2020). Safe haven, hedge and diversification for G7 stock markets: Gold versus bitcoin. Economic Modelling, 87, 212-224. https://doi.org/10.1016/j.econmod.2019.07.023

Shahzad, S. J. H., Bouri, E., Roubaud, D., Kristoufek, L., \& Lucey, B. (2019). Is Bitcoin a better safe-haven investment than gold and commodities? International Review of Financial Analysis, 63, 322-330. https://doi.org/10.1016/j.irfa.2019.01.002

Shaikh, I. (2020). Policy uncertainty and Bitcoin returns. Borsa Istanbul Review, 20(3), 257-268. https://doi.org/10.1016/j.bir.2020.02.003

Sharpe, W. F. (1964). Capital asset prices: A theory of market equilibrium under conditions of risk. Journal of Finance, 19(3), 425-442. https://doi.org/10.1111/j.1540-6261.1964.tb02865.x

Shukur, G., \& Mantalos, P. (1997). Size and power of the RESET test as applied to systems of equations: A bootstrap approach (Working Paper). Department of Statistics, University of Lund.

Shukur, G., \& Mantalos, P. (2000). A simple investigation of the Granger-causality test in integratedcointegrated VAR systems. Journal of Applied Statistics, 27(8), 1021-1031. https://doi.org/10.1080/02664760050173346

Su, C. W., Qin, M., Tao, R., \& Umar, M. (2020a). Does oil price really matter for the wage arrears in Russia? Energy, 208, 118350. https://doi.org/10.1016/j.energy.2020.118350

Su, C. W., Qin, M., Tao, R., \& Umar, M. (2020b). Financial implications of fourth industrial revolution: Can bitcoin improve prospects of energy investment? Technological Forecasting \& Social Change, 158, 120178. https://doi.org/10.1016/j.techfore.2020.120178

Su, C. W., Qin, M., Tao, R., Nicoleta-Claudia, M., \& Oana-Ramona, L. (2020c). Factors driving oil price - From the perspective of united states. Energy, 197, 117219.

https://doi.org/10.1016/j.energy.2020.117219

Su, C. W., Qin, M., Tao, R., Shao, X. F., Albu, L. L., \& Umar, M. (2020d). Can Bitcoin hedge the risks of geopolitical events? Technological Forecasting and Social Change, 159, 120182. https://doi.org/10.1016/j.techfore.2020.120182

Su, C. W., Wang, X. Q., Tao, R., \& Oana-Ramona, L. (2019). Do oil prices drive agricultural commodity prices? Further evidence in a global bio-energy context. Energy, 172, 691-701. https://doi.org/10.1016/j.energy.2019.02.028

Xiong, J. W., Liu, Q., \& Zhao, L. (2019). A new method to verify Bitcoin bubbles: Based on the production cost. North American Journal of Economics and Finance, 51, 101095. https://doi.org/10.1016/j.najef.2019.101095

Yen, K. C., \& Cheng, H. P. (2020). Economic policy uncertainty and cryptocurrency volatility. Finance Research Letters, 101428 (in Press). https://doi.org/10.1016/j.frl.2020.101428 